Line 1 is also used for indicating speech overlap, latching (lack of perceivable pause across a turn boundary), dysfluencies such as false-starts, and other details relevant to the analysis of discursive interaction (for theoretical and methodological reflections on transcription, see, for example, Ochs 1979; Edwards and Lampert 1993; Duranti 1997:137-54). For vocalizations such as filled pauses and backchannel cues, rough orthographic approximations are given, such as $a$ for $[\Lambda:]$ and ${ }^{\prime} m$ for $\left[\mathrm{Pm}^{2}\right]$. In the debate transcripts in chapter 2 , line breaks mark intonation unit boundaries, a unitization of discourse that is important for the study of interaction and for the analysis of phenomena like speech articulation rate.

For phonemic transcription in line 2, I have elected to use the simplified conventions found in Melvyn Goldstein's latest Tibetan-English dictionary (Goldstein, Shelling, and Surkhang 2001), in which tips on pronunciation can also be found. For simplicity, I do not represent the effects of phonological processes like vowel harmony, and while the transcription conventions from this latest dictionary are arguably not as helpful for linguists as those of the International Phonetics Alphabet or the Americanist conventions used in some of Goldstein's earlier dictionaries and in the classic work on Lhasa Tibetan phonology by Kun Chang and Betty Shefts Chang $(1964,1967)$, the improved accessibility seemed a worthwhile trade-off.

When I am not analyzing face-to-face interaction, I use orthographic transcription with free English translation, and when I mention Tibetan terms in the body of the text, I typically provide the orthographic form in italics after the English glosses. For proper names and for frequently used Tibetan terms, English approximations of Tibetan pronunciation are used (e.g., "Geluk" for $d g e$ lugs). The first time such names and terms are introduced, they are followed by their orthographic equivalent in parentheses or an endnote.

\title{
TRANSCRIPTION ABBREVIATIONS AND SYMBOLS
}

$\begin{array}{ll}\text { ABL } & \text { ablative } \\ \text { ACC } & \text { accusative } \\ \text { AGEN } & \text { agentive } \\ \text { ASR } & \text { assertoric mood } \\ \text { AUX } & \text { auxiliary verb } \\ \text { COND } & \text { conditional } \\ \text { CSQ } & \text { confirmation-seeking question } \\ \text { DAT } & \text { dative } \\ \text { DET } & \text { determiner } \\ \text { DIR } & \text { directive } \\ \text { DUBIT } & \text { dubitative mood } \\ \text { ERG } & \text { ergative } \\ \text { FCT } & \text { factive }\end{array}$




\begin{tabular}{|c|c|}
\hline GEN & genitive \\
\hline HON & honorific \\
\hline HON.A & addressee-focal honorific \\
\hline IEV & imperfective evidential \\
\hline IMP & imperative \\
\hline INJ & injunctive mood \\
\hline INS & instrumental \\
\hline INT & interrogative mood \\
\hline LOC & locative \\
\hline NEG & negation marker \\
\hline NH & non-honorific \\
\hline NOM & nomic evidential \\
\hline NP & noun phrase \\
\hline NZR & nominalizer \\
\hline $\mathrm{OPT}$ & optative \\
\hline $\mathrm{P}$ & participant-indexing (auxiliary verb) \\
\hline$\sim P$ & participant non-specific (auxiliary verb) \\
\hline PEV & perfective evidential \\
\hline PL & plural \\
\hline $\mathrm{PN}$ & proper name \\
\hline PRC & precative \\
\hline PRP & participant role perspective \\
\hline QT & quotative clitic \\
\hline TOP & topicalizer \\
\hline VLQ & volunteering question \\
\hline WHQ & WH question \\
\hline YNQ & yes/no question \\
\hline$\{\ldots / \ldots\}$ & paradigmatic contrast \\
\hline [ ] & author's interpolations \\
\hline : & lengthening \\
\hline [line break] & intonational unit boundary (debate transcripts only) \\
\hline / & $\begin{array}{l}\text { vertical line termed shad in Tibetan, which typically marks } \\
\text { clause and sentence boundaries }\end{array}$ \\
\hline ') & $\begin{array}{l}\text { latching (lack of perceivable pause between utterances; } \\
\text { less than } 1 / 10 \text { of second) }\end{array}$ \\
\hline
\end{tabular}

\section{STATEMENT OF METHODS}

By necessity this work operates at the intersection of disciplines. I am indebted to and engage literature in Tibetan and Buddhist studies, but the book's home is anthropology, especially the subfield of linguistic anthropology. The chapters that fol- 
low may be considered, more specifically, essays in-perhaps, toward-an anthropology of interaction.

Why privilege face-to-face interaction? There is ample empirical motivation for this focus, since interaction is, after all, something Tibetans reflect on and care about, but this focus is also likely a reaction to the kind of textualism I experienced, and practiced, when I started doctoral work in Buddhist studies. At that time I found myself caught up in emerging critiques of the field mounted by those within it, critiques that targeted the field's textualism and supposed orientalism. It was in this period of ferment that works like Donald Lopez's (1998) Prisoners of Shangri-La appeared, followed by a string of volumes that announced a turn toward "practice" (e.g., Lopez's Religions of Tibet in Practice in 1997 and Asian Religions in Practice in 1999). Whatever field-specific purchase a notion like "practice" may have had, and arguably still has, it rarely seemed to mean, to put it crudely, what people "do"-at least not as studied through the craft of observation, recording, transcription, and analysis. (I should add that I harbor no positivist pretensions about transcription and analysis, as I hope will be apparent in the chapters that follow.) In privileging text-artifacts (Silverstein and Urban 1996) Buddhist studies appears to have remained methodologically textualist, listing either toward the "secular," historicalphilological side or else toward the "religious," doctrinal-philosophical.

When it comes to interaction, anthropology has fared little better. Cultural anthropologists continue to rely-quite unreflectively, I should add-on interaction at every turn, from interviews to oral narratives to words culled from casual conversation. Though interaction is the empirical stuff from which ethnography is made, its pride of place is only rarely made explicit. What is more, there is a pernicious way in which folk ideologies of interaction and communication creep into arguments about the way macrosocial institutions and groups "interact." Even in linguistic anthropology, interaction remains a somewhat neglected area relative to linguistics and especially sociology; sociology's research tradition called "conversation analysis" has been extremely productive, to say nothing of the enormous influence of Erving Goffman's dramaturgical "micro"-sociology. While I work within linguistic anthropology, like many of my colleagues I draw liberally on adjacent research traditions such as interactional sociolinguistics, discourse analysis, and the ethnography of communication, even if none of these is quite expansive enough to accommodate the kinds of questions that concern contemporary anthropology.

Of all the reasons anthropologists use to justify their neglect of interaction, the most specious involves interaction's "scale." Entire research traditions (e.g., symbolic interactionism, conversation analysis, interactional sociolinguistics) have come into being with the aim of teasing out interaction's rules and regularities; they circumscribe interaction, making a neat domain of it. To be sure, many in response now wish to escape precisely these limits. They no longer want to treat "the interaction order" (Goffman 1983) as if it were some watertight chamber of activity in- 
sulated from the dynamics and pressures of macrosocial formations, yet in their rush to bridge "micro" and "macro" or to explore the supposed "dialectic" between the two, they continue to presume interaction's diminutive size. By leaving scale as an empirical question (Latour 2005; Lempert 2012b), not a problem to be solved in advance with the aid of prefabricated scalar distinctions (micro-, meso-, macro-), I aspire toward an anthropology of interaction more alive to interaction's "entanglements" (Maurer 2005).

Another reason some cite for this neglect of discursive interaction is not altogether unsound. Many feel that too much attention to the formal patterning of language use, coupled with an exaggerated faith in the fidelity of transcripts that borders on fetishization, encourages a blinkered aesthetics of sign behavior, perhaps even a kind of semiotic voyeurism. Marvel at the elegance and orderliness of signs, and you return to the rarefied heights of structuralism, confirming what many have long feared about semiotics: that it means the "autonomization of the sphere of meaning" (Latour 1993:62-63; see Ortner 1994; Parmentier 1997). For several decades now, linguistic and semiotic anthropologists have insisted that "semiotic mediation" (see Mertz and Parmentier 1985; Mertz 2007b) does not mean the study of some underlying, autonomous, immaterial "code" that is seamless and shared by a population. Still, if, in our writing, we dwell too long on transcripts and fail to experiment with integrating the analysis of these artifacts with other modes of writing, it becomes difficult to dismiss the criticism that we are, willy-nilly, severing discursive interaction from its surround and treating it as an autonomous domain.

Since this book is just as much a work in Tibetan and Buddhist studies-and in the small but emerging literature in the "anthropology of Buddhism"-as in linguistic anthropology, I recognize that many readers will be unfamiliar with methods for analyzing discursive interaction. As linguistic anthropologists have long argued, one cannot jump to function (what signs "do") without copious attention to form, but I have tried to strike a balance between the close, thick, transcriptcentered description of language use and more familiar modes of narration, especially the ethnographic and occasionally the historiographic. For those impatient with transcripts, it is possible to skate around those sections of the book, which form the core of chapters 2 (on debate) and 4 (on public reprimand). In the interest of promoting exchange across fields, I have also tried to limit my engagement with linguistic-anthropological theory.

This book draws on over two and a half years of contact with and research on Tibetans in South Asia that stretch back over two decades, with the core of the fieldwork carried out in 1998 and 2000-2001. The corpus of fieldwork data includes video, audio, and textual material. In terms of Buddhist debate (the most intricate of the interaction rituals I examined), I recorded roughly 55 hours of video footage, consisting primarily of debates from Sera Monastery and monasteries in Dharamsala, including at the Institute of Buddhist Dialectics. At Sera and in Dharamsala, 
debates were originally selected based on several dimensions of expected variation, including (a) debate type (e.g., daily courtyard debate versus formal, indoor debates) and (b) relative status between interactants, reckoned in terms of age, seniority, and religious rank (recognized reincarnated lamas versus ordinary monks). For comparative purposes I recorded debates from nine other sites across India, six of which were monasteries of the Geluk sect (the sect to which Sera belongs); two were Geluk nunneries that offer debate; and one was a monastery of the Nyingma sect near Sera. In terms of audio data, approximately 170 hours were recorded, which include interviews, playback-elicitation sessions (where I asked monks to comment on recordings), narratives, and oral histories. I also collected a wide range of textual materials, including a five-volume published collection of public addresses in Tibetan by the Dalai Lama, extending over forty years (1959-2000), brochures and monastic histories in Tibetan, Tibetan-language newspapers and magazines from the late 1960 s onward, and records kept at Sera that supply demographic facts about monks who join the monastery. Copious field notes were kept during every phase of my fieldwork.

I observed and transcribed many events but had to be extremely selective about which moments to include in the pages that follow. For purposes of exposition I chose to be faithful to the specificity of a few moments, to spend more time on their textures and qualities rather than race through many events in a bid to show how I "generalize." About the project's historical limits: This book stops at 2001, the year I returned from fieldwork. I do not address developments of the past decade. As with all fieldwork, this research consists of a series of moments in time and aspires to be nothing more, or less. 


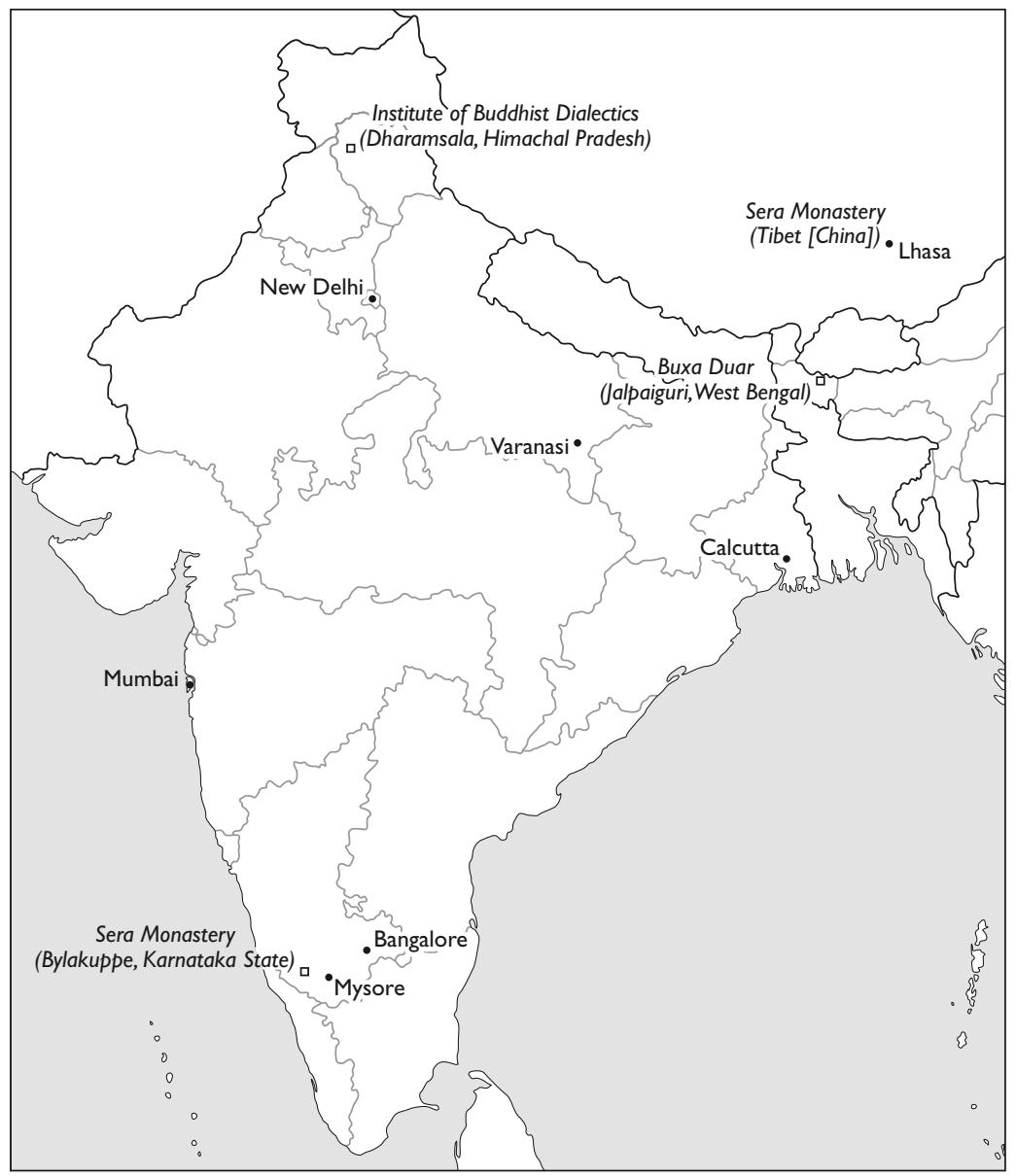

Primary monasteries and field sites discussed in this book 